\title{
Preparation of Doublet Microtubule Fraction for Single Particle Cryo-electron Microscopy
}

Corbin Black ${ }^{1, ~ \#, ~ D a n i e l ~ C h e n ~ D a i ~}{ }^{1}$, , Katya Peri ${ }^{1}$, Muneyoshi Ichikawa ${ }^{2,3, *}$ and Khanh Huy Bui ${ }^{11, *}$

1Department of Anatomy and Cell Biology, McGill University, Montréal, Canada; ${ }^{2}$ Division of Biological Science, Graduate School of Science and Technology, Nara Institute of Science and Technology, Takayama-cho, Ikoma, Nara, Japan; ${ }^{3}$ PRESTO, Japan Science and Technology Agency, Kawaguchi, Saitama, Japan

*For correspondence: michikawa@bs.naist.jp; huy.bui@mcgill.ca

\#Contributed equally to this work

[Abstract] Over the years, studying the ultrastructure of the eukaryotic cilia/flagella using electron microscopy (EM) has contributed significantly toward our understanding of ciliary function. Major complexes in the cilia, such as inner and outer dynein arms, radial spokes, and dynein regulatory complexes, were originally discovered by EM. Classical resin-embedding EM or cryo-electron tomography can be performed directly on the isolated cilia or in some cases, cilia directly attached to the cell body. Recently, single particle cryo-EM has emerged as a powerful structural technique to elucidate high-resolution structures of macromolecular complexes; however, single particle cryo-EM requires non-overlapping complexes, i.e., the doublet microtubule of the cilia. Here, we present a protocol to separate the doublet microtubule from the isolated cilia bundle of two species, Tetrahymena thermophila and Chlamydomonas reinhardtii, using ATP reactivation and sonication. Our approach produces good distribution and random orientation of the doublet microtubule fragments, which is suitable for single particle cryo-EM analysis.

Keywords: Tetrahymena thermophila, Chlamydomonas reinhardtii, Cilia, Flagella, Doublet microtubule, Cryo-EM, Mass spectrometry

[Background] Cilia are hairlike organelles that exist on the surface of cells and are responsible for motility and sensory functions. Cilia consist of a bundle of nine doublet microtubules surrounding the two central singlet microtubules in the case of motile cilia. Cilia comprise hundreds of unique protein molecules. Due to this complexity, the structural biology of cilia mainly relies on isolation of the intact cilia (Craige et al., 2013; Gaertig et al., 2013). In the last 15 years, cryo-electron tomography aided by subtomogram averaging has been a major force in pushing the molecular architecture of the intact eukaryotic cilia (Bui et al., 2008; Heuser et al., 2009; Imhof et al., 2019). However, the resolution of cryoelectron tomography is typically in the range of $20-40 \AA$, which limits the ability to create precise atomic models of the proteins in the cilia or interactions between different proteins for the mechanistic understanding of its function. Recently, advances in the single particle cryo-electron microscopy (cryoEM) technique have allowed high-resolution structures of macromolecular complexes typically in the range of 3-4 $\AA$; however, single particle cryo-EM does not work with the entire cilia due to the overlapping 
of the doublet microtubules. Our method of doublet microtubule purification and fractionation for cryoEM overcomes this limitation by splitting the doublet microtubules out of the cilia. This is facilitated by reactivation of dyneins using ATP, sonication, and salt extraction (Figure 1), which produces wellseparated fragments of the doublet microtubules suitable for single-particle cryo-EM (Ichikawa et al., 2017) (Figure 2). In fact, this allows the reconstruction of the doublet microtubule structures of both Chlamydomonas and Tetrahymena to 3-4 $\AA$ resolution and the visualization of the microtubule proteins inside the doublet (Ichikawa et al., 2019; Khalifa et al., 2020). In addition, these doublet microtubule purification protocols are suitable for proteomics analyses of the central pairs and microtubule inner proteins because they enrich those proteins during the salt wash of all the outer and inner dynein arm components (Dai et al., 2020).

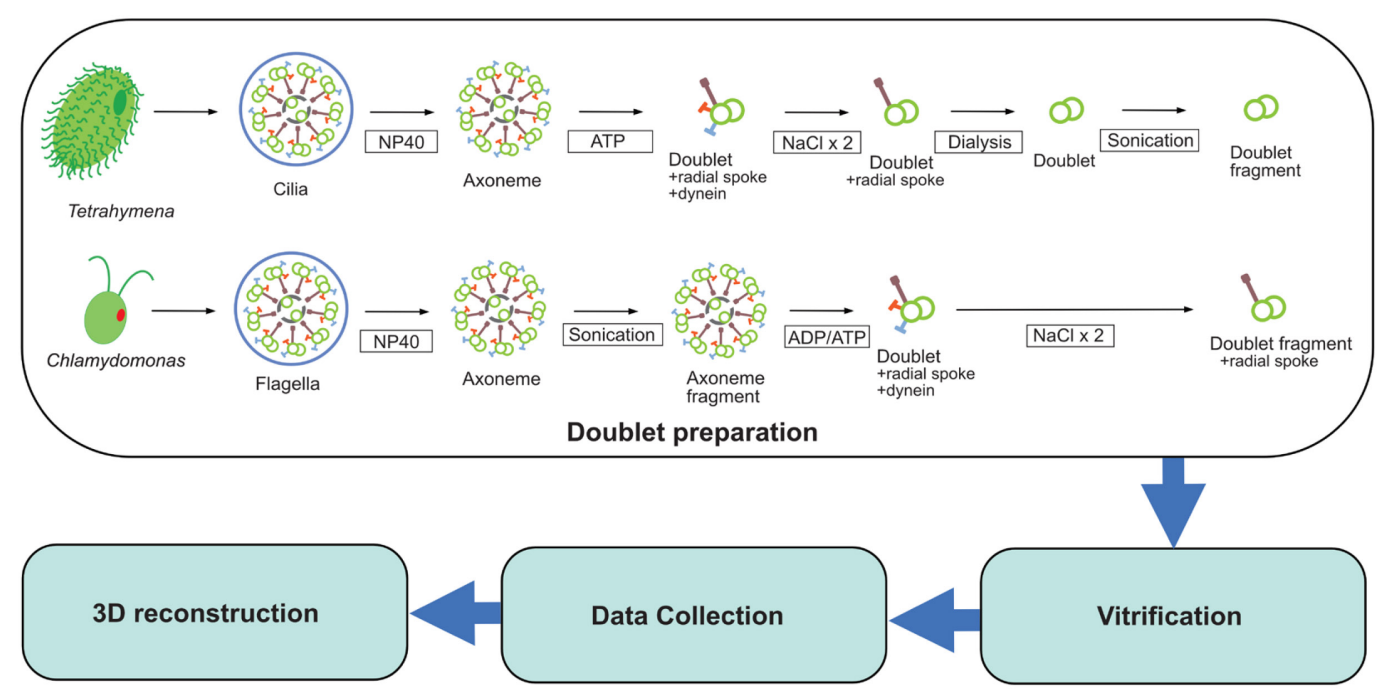

Figure 1. The workflow of the sample preparation for cryo-EM

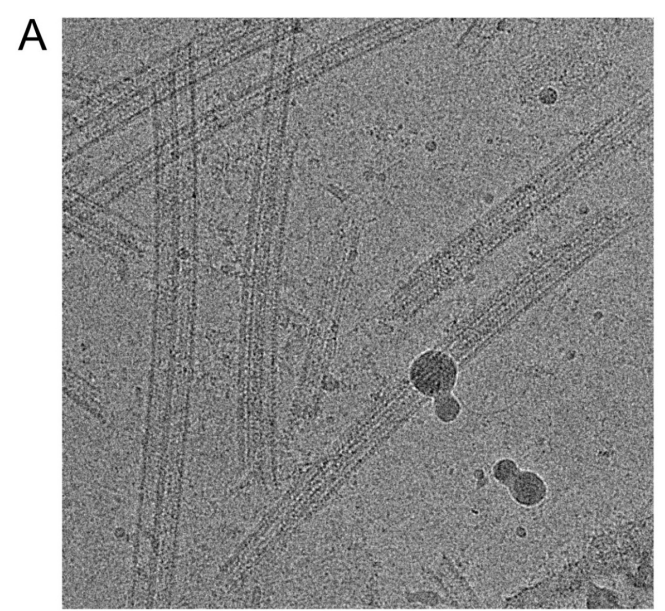

Tetrahymena

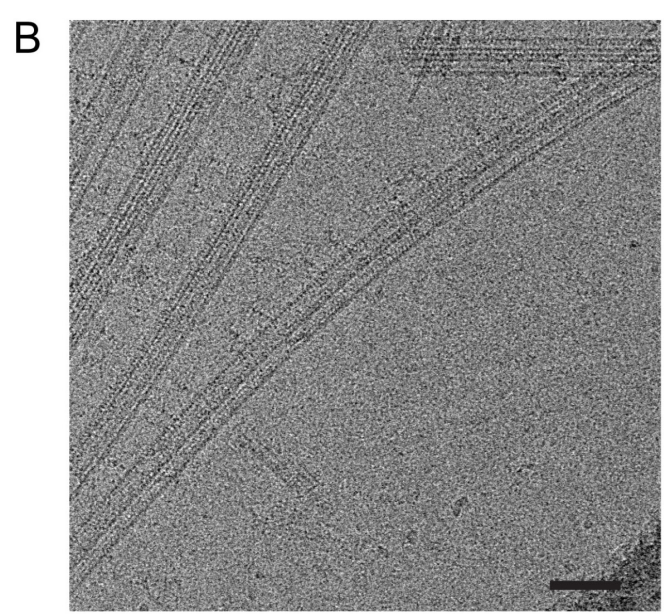

Chlamydomonas

Figure 2. Cryo-EM images of the Tetrahymena (A) and Chlamydomonas (B) doublet fragments. Scale bar: $50 \mathrm{~nm}$. 


\section{Materials and Reagents}

A. Tetrahymena doublet purification

1. 24-well cell culture plate (Millipore Sigma, catalog number: CLS3527)

2. SnakeSkin Dialysis Tubing, $10 \mathrm{~K}$ MWCO, $22 \mathrm{~mm}$ (Thermo Fisher Scientific, catalog number: 68100)

3. Tetrahymena thermophila cells (Tetrahymena Stock Center, SB255 mucocyst-free strain) Note: Our protocol works best with the SB255 strain rather than strains with mucocyst.

4. Proteose Peptone No. 3 (Thermo Fisher Scientific, catalog number: 211693)

5. Glucose (Research Products International, catalog number: G32040)

6. Yeast Extract (Thermo Fisher Scientific, catalog number: 211929)

7. Ethylenediaminetetraacetic acid iron (III) sodium salt, Fe-EDTA (Millipore Sigma, catalog number: EDFS)

8. Dibucaine Hydrochloride (Millipore Sigma, catalog number: D0638)

9. 4-(2-hydroxyethyl)-1-piperazineethanesulfonic acid [HEPES]

10. $\mathrm{MgSO}_{4}$ (Thermo Fisher Scientific, catalog number: AC447165000)

11. Ethylene glycol-bis(2-aminoethylether)-N,N,N',N'-tetraacetic acid, EGTA (Millipore Sigma, catalog number: E4378)

12. Dithiothreitol, DTT (Millipore Sigma, catalog number: 11583786001)

13. Sucrose (Research Products International, catalog number: S24060)

14. Trehalose (Research Products International, catalog number: T82000)

15. Phenylmethylsulfonyl fluoride [PMSF] (Millipore Sigma, catalog number: 52332)

16. $10 \%$ NP-40 Alternative (Millipore Sigma, catalog number: 492016)

17. 40 mM Adenosine triphosphate [ATP] (Millipore Sigma, catalog number: A2383)

18. SPP Liquid Media (see Recipes)

19. $25 \mathrm{mg} / \mathrm{ml}$ Dibucaine (see Recipes)

20. Cilia Wash Buffer (see Recipes)

21. Cilia Final Buffer (see Recipes)

22. Dialysis Buffer (see Recipes)

B. Chlamydomonas doublet purification

1. SnakeSkin Dialysis Tubing, $10 \mathrm{~K}$ MWCO, $22 \mathrm{~mm}$ (Thermo Fisher Scientific, catalog number: 68100)

2. Wild type Chlamydomonas Cells (Chlamydomonas resource center, CC-124 wild type mt-[137c]) Note: Our protocol also works with other Chlamydomonas strains with flagella or some strains that do not grow flagella under normal culture conditions.

3. Tris base (BioShop, catalog number: TRS001.5)

4. $\mathrm{NH}_{4} \mathrm{Cl}$ (BioShop, catalog number: AMC303.1)

5. $\mathrm{MgSO}_{4}$ (BioShop, catalog number: MAG522.1) 
6. $\mathrm{CaCl}_{2} \cdot 2 \mathrm{H}_{2} \mathrm{O}$ (BioShop, catalog number: CCL302.1)

7. $\mathrm{K}_{2} \mathrm{HPO}_{4}$ (BioShop, catalog number: PPD303.1)

8. $\mathrm{KH}_{2} \mathrm{PO}_{4}$ (BioShop, catalog number: PPM666.1)

9. Potassium Hydroxide, $\mathrm{KOH}$ (Thermo Fisher Scientific, catalog number: P2501)

10. Acetic Acid, $\mathrm{CH}_{3} \mathrm{COOH}$ (Thermo Fisher Scientific, catalog number: FLA38212)

11. Sodium Chloride, $\mathrm{NaCl}$ (BioShop, catalog number: SOD001.5)

12. Aprotinin (Millipore Sigma, catalog number: A1153)

13. Leupeptin (Millipore Sigma, catalog number: L2884)

14. Potassium acetate (BioShop, catalog number: POA303.5)

15. Polyethylene glycol, MW 20,000 (Millipore Sigma, catalog number: 817018)

16. Paclitaxel (Millipore Sigma, catalog number: T7402)

17. PMSF (Millipore Sigma, catalog number: 52332)

18. $10 \%$ NP-40 Alternative (Millipore Sigma, catalog number: 492016)

19. $100 \mathrm{mM}$ Adenosine di-phosphate [ADP] (Millipore Sigma, catalog number: A2754)

20. 10 mM ATP (Millipore Sigma, catalog number: A2383)

21. Tris-acetatephophate (TAP) salt solution (see Recipes)

22. Phosphate solution (see Recipes)

23. TAP liquid media (see Recipes)

24. $500 \mathrm{mM}$ Potassium Hydroxide (KOH) (see Recipes)

25. $500 \mathrm{mM}$ Acetic Acid $\left(\mathrm{CH}_{3} \mathrm{COOH}\right)$ (see Recipes)

26. $3 \mathrm{M}$ Sodium Chloride (3 M NaCl) (see Recipes)

27. HMDS solution (see Recipes)

28. HMDEKP solution (see Recipes)

\section{Equipment}

A. Tetrahymena doublet purification

1. 250-ml Erlenmeyer flask (Millipore Sigma, catalog number: CLS4980250)

2. 500-ml Erlenmeyer flask

3. Floor shaker (Thermo Scientific, model: MAXQ8000)

4. Spectrophotometer (Thermo Scientific, model: 840-208100 UV/Vis)

5. Floor centrifuge (Beckman Coulter, model: Avanti J-20 XP, Rotors JLA-8.1 and JA25.5)

6. Tabletop centrifuge (Thermo Scientific, model: Sorvall ST 16R, Rotor 75003181)

7. Microfuge (Eppendorf, model: Centrifuge 5415 D, Rotor F45-24-11)

8. $\mathrm{pH}$ meter (Hanna HI 2210 Benchtop pH/Temperature Meter)

9. Sonicator (Fisher Scientific Sonic Dismembrator Model 100)

B. Chlamydomonas doublet purification

1. Floor shaker (Thermo Scientific, model: MAXQ8000) 
2. Spectrophotometer (Thermo Scientific, model: 840-208100 UV/Vis)

3. Floor centrifuge (Beckman Coulter, model: Avanti J-20 XP, Rotor JLA-8.1, Rotor JA25.5)

4. Tabletop centrifuge (Thermo Scientific, model: Sorvall ST 16R, Rotor 75003181)

5. Microcentrifuge (Eppendorf, model: Centrifuge 5415 D, Rotor F45-24-11)

6. $\mathrm{pH}$ meter (Hanna HI 2210 Benchtop $\mathrm{pH} /$ Temperature Meter)

7. Sonicator (Fisher Scientific Sonic Dismembrator Model 100)

\section{Procedure}

A. Tetrahymena doublet purification

1. Growth of Tetrahymena cells for isolation

a. Tetrahymena cells (SB255 or CU-428) are stored in bean media (Williams et al., 1980).

b. Transfer $50 \mu \mathrm{l}$ bean media into $1 \mathrm{ml}$ SPP media in a 24-well cell culture plate. Culture at room temperature (RT) for 4-5 days until the cells reach a density of $1.6 \times 10^{6} \mathrm{cells} / \mathrm{ml}$. Note: Observe the health of the cells under a light microscope before Step A1c.

c. Transfer $40 \mu \mathrm{l}$ saturated Tetrahymena cells to $40 \mathrm{ml}$ liquid SPP media in a 250-ml Erlenmeyer flask and grow for approximately one week at RT.

Note: $40 \mu \mathrm{l}$ saturated Tetrahymena cells can be passaged to another $40 \mathrm{ml}$ liquid SPP media in a 500-ml Erlenmeyer flask and kept for about one week at RT or for several weeks at 15$16^{\circ} \mathrm{C}$.

d. Transfer $2 \mathrm{ml}$ saturated cells from the $40 \mathrm{ml}$ RT culture into $100 \mathrm{ml}$ liquid SPP media and grow overnight with shaking at $150 \mathrm{rpm}$ and $30^{\circ} \mathrm{C}$ in the MAXQ8000 shaker incubator (Figure 3A).

e. Add the entire $100 \mathrm{ml}$ overnight culture to $1 \mathrm{~L}$ liquid SPP media and grow for approximately 2 days with shaking at $150 \mathrm{rpm}$ and $30^{\circ} \mathrm{C}$ (MAXQ8000). The optimal $\mathrm{OD}_{600}$ is 0.7 .

f. Incubate cells at $15^{\circ} \mathrm{C}$ with shaking for 30 min to $1 \mathrm{~h}$ (Figure $3 \mathrm{~B}$ ).

2. Cilia isolation by dibucaine treatment

a. Divide the entire cell culture into 2 or 4 equal volumes and pour into appropriate centrifuge tubes. Centrifuge at $700 \times g$ for $10 \mathrm{~min}$ at $4^{\circ} \mathrm{C}$ with slow deceleration using the Avanti, Rotor JLA-8.1.

Note: After this step, keep the cells at $4^{\circ} \mathrm{C}$ or on ice to minimize the secretion of mucus.

b. Resuspend pellet containing cells with $10 \mathrm{ml}$ ice-cold SPP media and then adjust the total volume of solution to $24 \mathrm{ml}$.

c. Transfer the $24 \mathrm{ml}$ resuspended cells into a 250-ml Erlenmeyer flask on ice (Figure 3C).

d. Have the $1 \mathrm{ml}$ dibucaine $(25 \mathrm{mg} / \mathrm{ml})$ and $75 \mathrm{ml}$ ice-cold liquid SPP media ready.

e. Quickly add the $1 \mathrm{ml}$ dibucaine to the $24 \mathrm{ml}$ resuspended cells (final $1 \mathrm{mg} / \mathrm{ml}$ dibucaine) and swirl the flask for exactly $1 \mathrm{~min}$.

f. Quickly add $75 \mathrm{ml}$ ice-cold liquid SPP media to stop the reaction and transfer the whole cilia solution into two centrifuge tubes for the Beckman Coulter JA25.5 rotor. 
g. Centrifuge the entire cilia suspension at $2,000 \times g$ for 10 min at $4^{\circ} \mathrm{C}$ with slow deceleration (Avanti, Rotor JA25.5) (Figure 3D).

h. Using a pipet gun, carefully aspirate the cilia-containing supernatant without disturbing the cellular debris and mucus. Divide the supernatant into 4 equal volumes in centrifuge tubes for the Beckman Coulter JA25.5 rotor, approximately $20 \mathrm{ml}$ per centrifuge tube.

i. Centrifuge the cilia suspension at $17,000 \times g$ for 40 min at $4^{\circ} \mathrm{C}$ with slow deceleration using the Avanti, Rotor JA25.5 (Figure 3E).

j. Remove the supernatant and gently wash away the transparent layer of mucus around the cilia pellet using a pipet and $100 \mu \mathrm{l}$ volumes of ice-cold Cilia Wash Buffer. When the cilia pellet is clean, resuspend it with $250 \mu$ ice-cold Cilia Wash Buffer for each centrifuge tube and resuspend the cilia pellet (total $1 \mathrm{ml}$ ).

k. Transfer the cilia solution into two $1.5-\mathrm{ml}$ microcentrifuge tubes $(\sim 500 \mu \mathrm{l}$ each) and centrifuge the cilia suspension at $7,800 \times \mathrm{g}$ for $10 \mathrm{~min}$ at $4^{\circ} \mathrm{C}$ in a microfuge (Eppendorf, Centrifuge 5415 D).

I. Remove the supernatant and resuspend the cilia pellet in $250 \mu$ cilia wash buffer (Figure 3F).

Note: The cilia pellet can be snap frozen here with liquid nitrogen and stored at $-80^{\circ} \mathrm{C}$, but the splitting works best with cilia without freezing. 


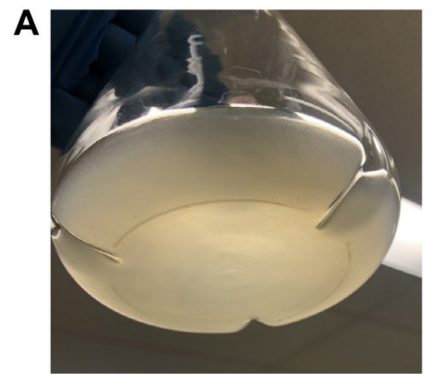

$100 \mathrm{~mL}$ small culture

C before transfer

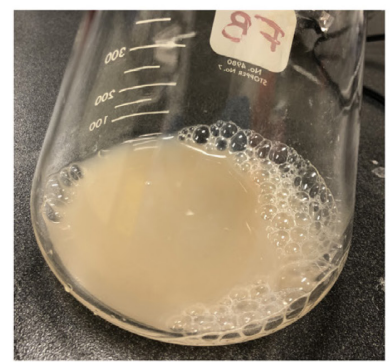

Suspension before dibucaine treatment

D

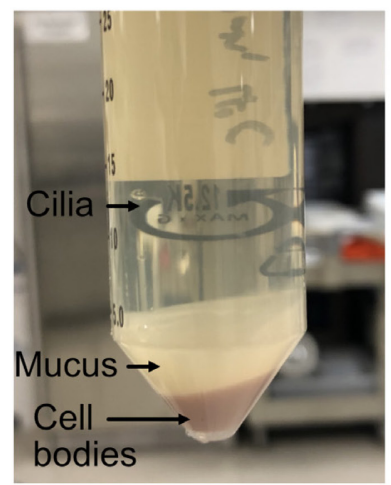

Centrifugation after dibucaine treatment

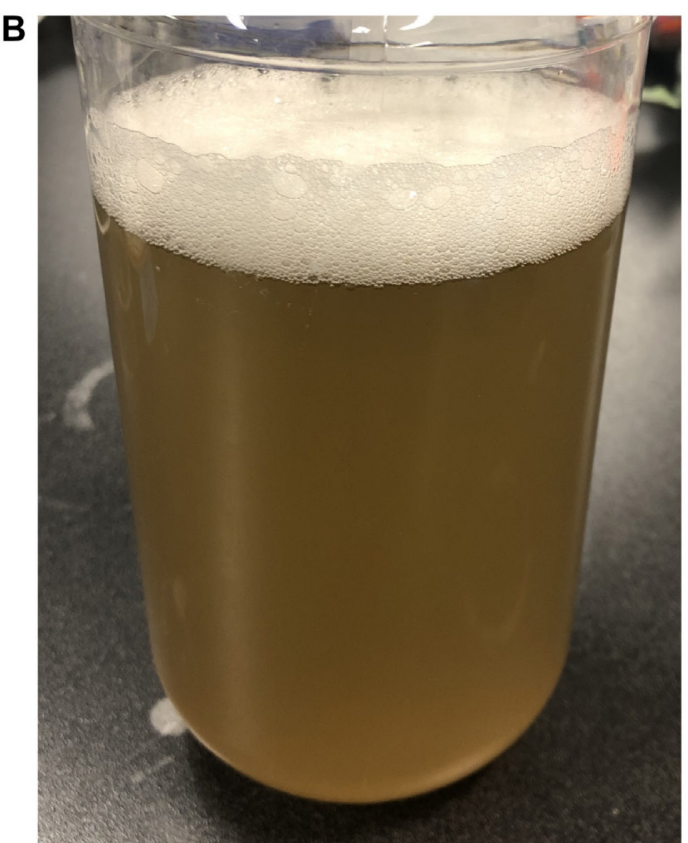

Large culture after $48 \mathrm{hr}$

E

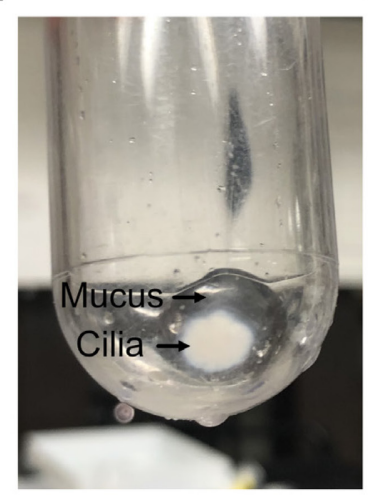

Centrifugation of cilia
$\mathbf{F}$

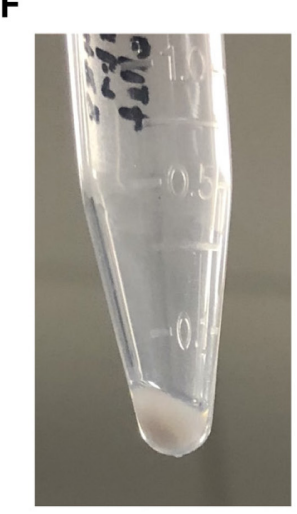

Final cilia pellet

Figure 3. Purification of Tetrahymena cilia with dibucaine. Images depict Tetrahymena cell cultures (A-B), cell suspension before dibucaine treatment $(C)$, pellet and supernatant after dibucaine treatment $(D)$, and cilia pellet before $(E)$ and after final washing $(F)$.

3. Purification of doublet microtubule fraction

a. Resuspend the cilia pellet to $250 \mu$ with Cilia Final Buffer for each tube.

Note: From here, the amounts are for each tube.

b. Add $44.1 \mu \mathrm{l} 10 \% \mathrm{NP}-40$ alternative (final concentration of $1.5 \% \mathrm{NP}-40$ ) and resuspend the total solution. Incubate on ice for $30 \mathrm{~min}$ to de-membrane the cilia.

c. Centrifuge at $7,800 \times g$ for $10 \mathrm{~min}$ at $4^{\circ} \mathrm{C}$ in a microfuge (Eppendorf, Centrifuge $5415 \mathrm{D}$ ).

d. Remove the supernatant and resuspend the pellet to $247 \mu \mathrm{l}$ with Cilia Final Buffer.

e. Add $2.5 \mu \mathrm{l} 40 \mathrm{mM}$ ATP and incubate for $10 \mathrm{~min}$ at RT for the axoneme to split apart. 
f. Centrifuge at $16,000 \times g$ for $10 \mathrm{~min}$ at $4^{\circ} \mathrm{C}$ in a microcentrifuge (Eppendorf, Centrifuge 5415 D).

g. Remove the supernatant and resuspend the doublet microtubule pellet to $250 \mu \mathrm{l}$ with Cilia Final Buffer.

h. Add $62.5 \mu \mathrm{l} 3 \mathrm{M} \mathrm{NaCl}$ to a final concentration of $0.6 \mathrm{M} \mathrm{NaCl}$ and incubate on ice for $30 \mathrm{~min}$ to remove dyneins.

i. Centrifuge at $16,000 \times \mathrm{g}$ for $10 \mathrm{~min}$ at $4^{\circ} \mathrm{C}$ in the microcentrifuge (Eppendorf, Centrifuge 5415 D).

j. Remove the supernatant and resuspend the pellet to $250 \mu \mathrm{l}$ with Cilia Final Buffer.

k. Repeat Steps h-j.

I. $250 \mu$ doublet fractions are applied to the dialysis membrane and dialyzed against $200 \mathrm{ml}$ Dialysis buffer overnight at $4^{\circ} \mathrm{C}$ with stirring to deplete radial spokes.

$\mathrm{m}$. Collect sample from dialysis tube and centrifuge at $16,000 \times \mathrm{g}$ for $10 \mathrm{~min}$ at $4^{\circ} \mathrm{C}$ in the microcentrifuge (Eppendorf, Centrifuge 5415 D).

n. Remove the supernatant and resuspend the pellet to $250 \mu \mathrm{l}$ with Cilia Final Buffer.

Note: After dialysis, the purified doublet microtubule fraction with all the outside proteins is removed.

4. Sonication of the doublet microtubule for cryo-EM

a. Sonication conditions: power 4, $10 \mathrm{~s}$ (sample in 1.5-ml microtube on ice).

Note: Slightly move the probe inside the solution while sonicating.

b. Centrifuge at $2,000 \times g$ for $10 \mathrm{~min}$ at $4^{\circ} \mathrm{C}$ in the microcentrifuge (Eppendorf, Centrifuge 5415 D)

Note: This step only precipitates aggregated doublet fragments and depolymerized tubulin will stay in the supernatant.

c. Resuspend the doublet microtubule pellet to $25 \mu \mathrm{l}$ with Cilia Final Buffer (supplemented with $0.6 \mathrm{M} \mathrm{NaCl}$ ).

Note: $0.6 \mathrm{M} \mathrm{NaCl}$ helps the dissociation of aggregated doublet fragments.

d. Quantitate protein concentration (i.e., Bradford assay with spectrophotometer), then adjust the volume to the required concentration for application. For cryo-EM, $4 \mathrm{mg} / \mathrm{ml}$ sonicated Tetrahymena doublet fragments is appropriate. For mass spectrometry, $1 \mathrm{mg} / \mathrm{ml}$ sonicated doublet fragment is appropriate.

B. Chlamydomonas doublet purification

1. Growth of Chlamydomonas cells for isolation

a. Chlamydomonas cells are struck onto TAP solid plates containing $1.5 \%$ agar for storage.

b. Grow cells on TAP solid plates on a $12 \mathrm{~h}$ alternating light and dark cycle for approximately two weeks at RT.

c. Scrape off approximately 3-5 $\mathrm{mm}$ of cells and transfer to $50 \mathrm{ml}$ liquid TAP media then grow for one week with shaking or stirring conditions on $12 \mathrm{~h}$ alternating light and dark cycles at 


\section{RT (Figure 4A).}

Note: After one week, observe the health of the cells under a light microscope before Step B1d.

d. Remove $10 \mathrm{ml}$ of the $50 \mathrm{ml}$ liquid culture, transfer it to $1 \mathrm{LTAP}$ media, and grow with shaking or stirring conditions and $12 \mathrm{~h}$ alternating light and dark cycle at RT for approximately 4-6 days until the $\mathrm{OD}_{600}$ reaches $0.5-0.6$ (Figure 4B).

2. Flagella growth

Note: This step is optional and useful for Chlamydomonas mutant strains that do not grow flagella under normal culture conditions.

a. Centrifuge the $1 \mathrm{~L}$ Chlamydomonas culture at $700 \times g$ for $7 \mathrm{~min}$ at $4^{\circ} \mathrm{C}$ using the Avanti, Rotor JLA-8.1.

b. Resuspend the pellet in $50 \mathrm{ml}$ deionized water vigorously using a pipette gun and transfer into a $50-\mathrm{ml}$ conical tube.

Note: Pipet up and down 10 times to separate the cells.

c. Transfer $50 \mathrm{ml}$ resuspended cells into $1 \mathrm{~L}$ deionized water (with a stir bar) and wrap the entire flask with aluminum to prevent contact with light.

d. Place on a stirring or shaking platform and leave to incubate for 1-2 $\mathrm{h}$.

e. Observe the cells under a light microscope after the incubation period to see if Chlamydomonas cells are swimming.

3. Flagella isolation by $\mathrm{pH}$ shock

Note: We use $\mathrm{pH}$ shock because it gives us a cleaner doublet fraction with less protein contaminants, making it more suitable for mass spectrometry. The dibucaine method described for Tetrahymena can also be used.

a. Centrifuge the $1 \mathrm{~L}$ cell culture at $700 \times g$ for $7 \mathrm{~min}$ at $4^{\circ} \mathrm{C}$ using the Avanti, Rotor JLA-8.1 (Figure 4C).

Note: From here, keep the samples on ice or $4^{\circ} \mathrm{C}$.

b. Resuspend the pellet containing cells in 3-5 ml HMDS solution and transfer into a 50-ml conical tube.

c. Adjust the total volume of solution to $15 \mathrm{ml}$ using HMDS solution (with a small stir bar).

d. Adjust the $\mathrm{pH}$ of the solution to 4.5 with acetic acid and wait for 1 min using a $\mathrm{pH}$ probe with stirring.

e. Quickly adjust the $\mathrm{pH}$ of the solution to 7.5 with $0.5 \mathrm{M} \mathrm{KOH}$ and remove the stir bar.

f. Centrifuge the $\mathrm{pH}$-shocked solution at $1,800 \times \mathrm{g}$ at $5 \mathrm{~min}$ at $4^{\circ} \mathrm{C}$ (Sorvall ST $16 \mathrm{R}$, Rotor 75003181) with a deceleration power of 4 to remove the cell bodies (Figure 4D).

g. After centrifugation, the isolated flagella will be in the supernatant. Carefully transfer the supernatant to a new $50-\mathrm{ml}$ conical tube.

Note: Avoid any debris or pellet.

h. Centrifuge the supernatant at $4,700 \times g$ for 40 min at $4^{\circ} \mathrm{C}$ (Sorvall ST 16R, Rotor 75003181) with a deceleration power of 7 (Figure $4 \mathrm{E}$ ). 
i. The flagella are now pelleted. Remove the supernatant and resuspend the pellet in $500 \mu \mathrm{l}$ HMDEKP solution.

j. Transfer the flagella solution into a $1.5-\mathrm{ml}$ microcentrifuge tube and centrifuge at $7,800 \times g$ for $10 \mathrm{~min}$ at $4^{\circ} \mathrm{C}$ in the Eppendorf Centrifuge $5415 \mathrm{D}$ (Figure 4F).

Note: The green color of the pellet is from leakage of cell debris due to harsh dibucaine treatment or when working with some cell wall-less CLiP mutants (Chlamydomonas resource center). After the flagella are treated with NP-40 alternative and subsequently pelleted, the green color will not be present.

k. Remove the supernatant.

Note: Whole flagella pellet can be snap frozen here with liquid nitrogen and stored in the $80^{\circ} \mathrm{C}$; however, splitting of doublet works better with flagella without freezing and storage. 


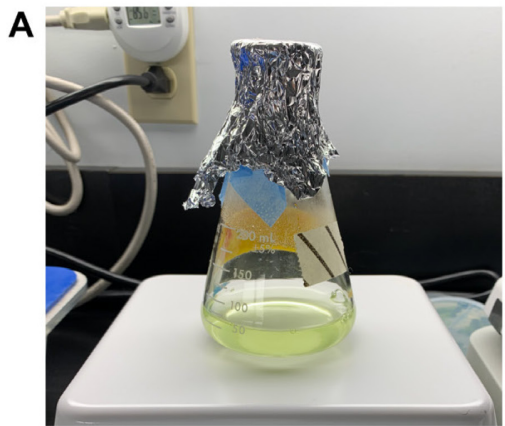

Pre-culture

\section{B}

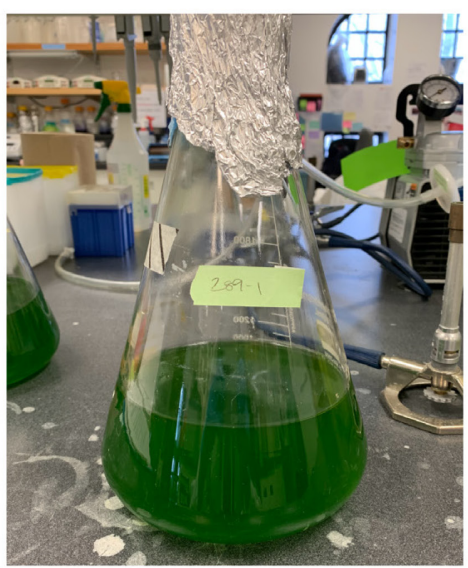

$1 \mathrm{~L}$ culture ready

C

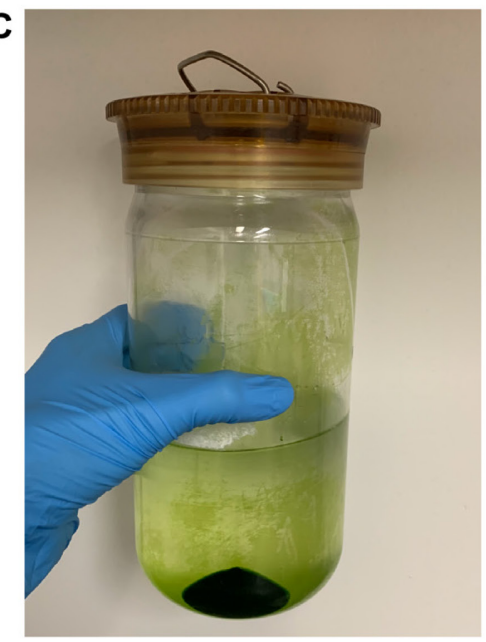

Centrifugation of culture

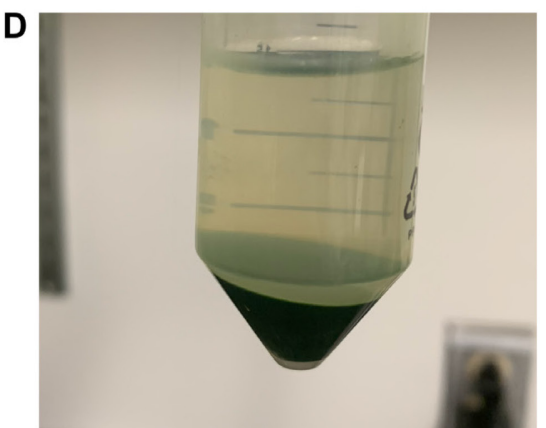

Centrifugation after $\mathrm{pH}$ shock

E

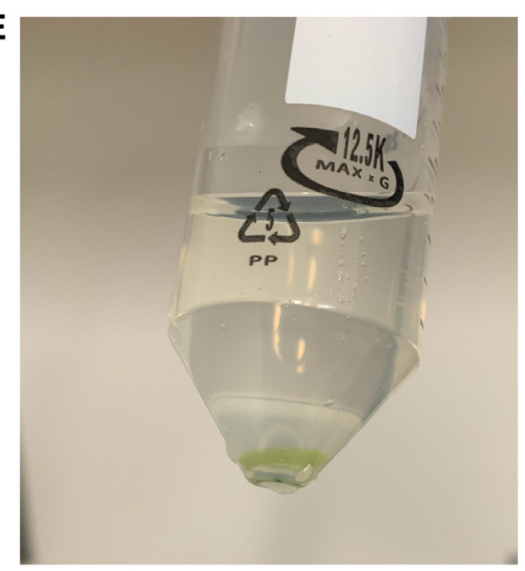

Centrifugation of flagella solution

$\mathbf{F}$

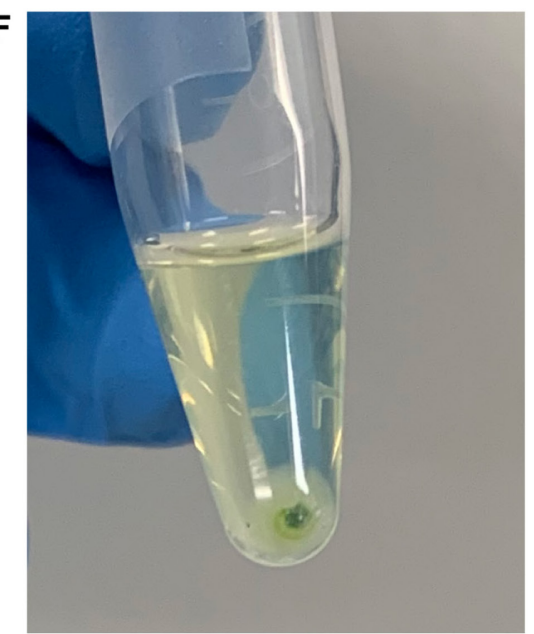

Final flagella pellet

Figure 4. Purification of Chlamydomonas cilia with pH shock. Images depict Chlamydomonas cell cultures (A-B), centrifugation of cell culture (C), centrifugation after $\mathrm{pH}$ shock $(D)$, and flagella pellet before $(E)$ and after washing $(F)$.

4. Purification of doublet microtubule fraction

a. Resuspend the flagella pellet to $250 \mu \mathrm{l}$ with HMDEKP.

b. Add $44.1 \mu \mathrm{l} 10 \% \mathrm{NP}-40$ alternative (final concentration of $1.5 \% \mathrm{NP}-40$ ) and resuspend the total solution. Incubate on ice for 30 min to get rid of the flagella membrane. 
C. Centrifuge at $7,800 \times \mathrm{g}$ for $10 \mathrm{~min}$ at $4^{\circ} \mathrm{C}$ in a microcentrifuge (Eppendorf, Centrifuge 5415 D).

d. Remove the supernatant and resuspend the pellet to $250 \mu \mathrm{l}$ with HMDEKP.

e. For cryo-EM, sonicate the flagella solution. Conditions specific to the Fisher Scientific Sonic Dismembrator Model 100: Small probe (1 $\mathrm{ml}$ volume), power 4, $10 \mathrm{~s}$ on ice.

Note: Slightly move the probe inside the solution while sonicating.

For Chlamydomonas doublet, sonication was done at an earlier step since it was harder to split.

f. Centrifuge at 2,000 $\times \mathrm{g}$ for $1 \mathrm{~min}$ at $4^{\circ} \mathrm{C}$ in the microcentrifuge (Eppendorf, Centrifuge 5415 D).

Note: This step only precipitates aggregated doublets but leaves tubulins in the supernatant.

g. Resuspend the doublet microtubule pellet to $250 \mu$ with HMDEKP solution.

h. Add $2.5 \mu \mathrm{l} 100 \mathrm{mM}$ ADP to a final concentration of $1 \mathrm{mM}$ ADP and incubate for $10 \mathrm{~min}$ at RT.

Note: This step is done only for Chlamydomonas doublet splitting to activate dyneins since it was harder to split.

i. Add $2.5 \mu \mathrm{l} 10 \mathrm{mM}$ ATP to a final concentration of $0.1 \mathrm{mM}$ ATP and incubate for another 10 min at RT for the doublet to split away from the flagella.

Note: Concentration of ATP is lower in the Chlamydomonas protocol to get higher activity of dyneins. We did not add protease for splitting since we found that the addition of elastase affects the structure of MIPs.

j. Centrifuge at $16,000 \times g$ for $10 \mathrm{~min}$ at $4^{\circ} \mathrm{C}$ in a microcentrifuge (Eppendorf, Centrifuge 5415 D).

k. Remove the supernatant and resuspend the pellet to $250 \mu \mathrm{l}$ with HMDEKP.

l. Add $62.5 \mu \mathrm{l} 3 \mathrm{M} \mathrm{NaCl}$ (final concentration of $0.6 \mathrm{M} \mathrm{NaCl}$ ) and incubate on ice for $30 \mathrm{~min}$.

$\mathrm{m}$. Centrifuge at $16,000 \times \mathrm{g}$ for $10 \mathrm{~min}$ at $4^{\circ} \mathrm{C}$ in the microcentrifuge (Eppendorf, Centrifuge $5415 \mathrm{D})$.

n. Remove the supernatant and resuspend the pellet to $250 \mu$ with HMDEKP buffer.

o. Repeat Steps B4I to B4n once more.

p. After the second salt wash, the final pellet will contain the purified doublet microtubule fraction with most of the outside proteins removed except for radial spokes.

Note: We tried several different conditions to remove radial spokes from Chlamydomonas doublets, but we were unable to remove radial spokes and keep Chlamydomonas doublet microtubules intact.

q. Quantitate protein concentration (i.e., Bradford assay with spectrophotometer), then adjust the volume to the required concentration for application. For cryo-EM, $4 \mathrm{mg} / \mathrm{ml}$ sonicated doublet fragments is appropriate. For mass spectrometry, $1 \mathrm{mg} / \mathrm{ml}$ sonicated doublet fragment is appropriate. 


\section{Notes}

In cryo-EM, obtained doublet microtubule fragments take random orientations in vitrifies ice compared with non-sonicated doublet microtubules (Figure 2). Tetrahymena doublet microtubule structure obtained with this procedure retained most of the MIPs except for inner junction (IJ) filament (FAP20/PACRG). In contrast, Chlamydomonas doublet structure retained IJ filament but some of the MIPs inside the A-tubule were lost (Ichikawa et al., 2017 and 2019; Khalifa et al., 2020).

\section{Recipes}

1. SPP Liquid Media (Gorovsky et al., 1975)

For $1 \mathrm{~L}$ media:

$1 \%$ Proteose Peptone No. $3,10 \mathrm{~g}$

$0.2 \%$ Glucose, $2 \mathrm{~g}$

$0.1 \%$ Yeast Extract, $1 \mathrm{~g}$

$0.003 \%$ Ethylenediaminetetraacetic acid iron (III) sodium salt [Fe-EDTA], $0.03 \mathrm{~g}$

Make up to $1 \mathrm{~L}$ with Milli-Q water and autoclave

2. $25 \mathrm{mg} / \mathrm{ml}$ Dibucaine

For $1 \mathrm{ml}$ :

Dibucaine Hydrochloride $0.025 \mathrm{~g}$

Make up to $1 \mathrm{ml}$ with SPP Liquid Media

3. Cilia Wash Buffer

50 mM 4-(2-hydroxyethyl)-1-piperazineethanesulfonic acid [HEPES], $\mathrm{pH} 7.4$

$3 \mathrm{mM} \mathrm{MgSO}_{4}$

$0.1 \mathrm{mM}$ Ethylene glycol-bis(2-aminoethylether)-N, N, N', $\mathrm{N}^{\prime}$-tetraacetic acid [EGTA]

$1 \mathrm{mM}$ dithiothreitol (DTT) (add fresh)

$250 \mathrm{mM}$ Sucrose

4. Cilia Final Buffer

50 mM HEPES, $\mathrm{pH} 7.4$

$3 \mathrm{mM} \mathrm{MgSO}_{4}$

$0.1 \mathrm{mM}$ EGTA

$1 \mathrm{mM}$ DTT (add fresh)

$0.5 \%$ Trehalose

$1 \mathrm{mM}$ PMSF (add fresh)

5. Dialysis Buffer

5 mM HEPES, pH 7.4

$1 \mathrm{mM}$ DTT (add fresh)

$0.5 \mathrm{mM}$ EDTA

6. Tris-acetatephophate (TAP) salt solution 
For $1 \mathrm{~L}$ :

$\mathrm{NH}_{4} \mathrm{Cl}, 15 \mathrm{~g}$

$\mathrm{MgSO}_{4}, 1.95 \mathrm{~g}$

$\mathrm{CaCl}_{2} \cdot 2 \mathrm{H}_{2} \mathrm{O}, 2 \mathrm{~g}$

Make up to $1 \mathrm{~L}$ with Milli-Q water

7. Phosphate solution

For $100 \mathrm{ml}$ :

$\mathrm{K}_{2} \mathrm{HPO}_{4}, 28.8 \mathrm{~g}$

$\mathrm{KH}_{2} \mathrm{PO}_{4}, 14.4 \mathrm{~g}$

Make up to $100 \mathrm{ml}$ with Milli-Q water

8. TAP liquid media (Gorman and Levine, 1965)

For $1 \mathrm{~L}$ media:

Tris base, $2.42 \mathrm{~g}$

TAP salt solution, $25 \mathrm{ml}$

Phosphate solution, $0.375 \mathrm{ml}$

Hutner's trace elements (Chlamydomonas resource center), $1.0 \mathrm{ml}$

Glacial acetic acid, $1.0 \mathrm{ml}$

Make up to $1 \mathrm{~L}$ with Milli-Q water and autoclave

Note: For TAP solid media, add $20 \mathrm{~g}$ Agar to this recipe.

9. $500 \mathrm{mM}$ Potassium Hydroxide $(\mathrm{KOH})$

10. $500 \mathrm{mM}$ Acetic Acid $\left(\mathrm{CH}_{3} \mathrm{COOH}\right)$

11. $3 \mathrm{M}$ Sodium Chloride ( $3 \mathrm{M} \mathrm{NaCl}$ )

12. HMDS solution

$10 \mathrm{mM}$ HEPES, $\mathrm{pH} 7.4$

$5 \mathrm{mM} \mathrm{MgSO}_{4}$

$1 \mathrm{mM}$ DTT (add fresh)

$4 \%$ sucrose

$10 \mu \mathrm{g} / \mathrm{ml}$ aprotinin (add fresh)

$5 \mu \mathrm{g} / \mathrm{ml}$ leupeptin (add fresh)

13. HMDEKP solution

$30 \mathrm{mM}$ HEPES, $\mathrm{pH} 7.4$

$5 \mathrm{mM} \mathrm{MgSO}_{4}$

$1 \mathrm{mM}$ DTT (add fresh)

$0.5 \mathrm{mM}$ EGTA

$25 \mathrm{mM}$ potassium acetate

$0.5 \%$ polyethylene glycol (MW 20,000)

$10 \mu \mathrm{M}$ paclitaxel (add fresh)

$1 \mathrm{mM}$ PMSF (add fresh)

$10 \mu \mathrm{g} / \mathrm{ml}$ aprotinin (add fresh) 
$5 \mu \mathrm{g} / \mathrm{ml}$ leupeptin (add fresh)

Note: Paclitaxel was added to the HMDEKP buffer for Chlamydomonas doublet preparation since it was less stable than the Tetrahymena doublet.

\section{Acknowledgments}

This research was financially supported by the Natural Sciences and Engineering Research Council of Canada (RGPIN-2016-04954), Canada Institute of Health Research (CIHR PJT-156354), and the Canada Institute for Advanced Research Arzieli Global Scholars Program to K.H.B. MI was supported by JST, PRESTO Grant Number JPMJPR20E1, JSPS KAKENHI Grant Numbers JP19K23726 and JP20K15733, and the Foundation for Nara Institute of Science and Technology (R2290001). This protocol was adapted with minor modification from previous study published by Khalifa et al. (2020).

\section{Competing interests}

The authors declare no conflicts of interests.

\section{References}

1 Bui, K. H., Sakakibara, H., Movassagh, T., Oiwa, K. and Ishikawa, T. (2008). Molecular architecture of inner dynein arms in situ in Chlamydomonas reinhardtii flagella. J Cell Biol 183(5): 923-932.

2 Craige, B., Brown, J. M. and Witman, G. B. (2013). Isolation of Chlamydomonas flagella. Curr Protoc Cell Biol Chapter 3: Unit 341 41-49.

3 Dai, D., Ichikawa, M., Peri, K., Rebinsky, R. and Bui, K. H. (2020). Identification and mapping of central pair proteins by proteomic analysis. Biophys Physicobiol 17: 71-85.

4 Gaertig, J., Wloga, D., Vasudevan, K. K., Guha, M. and Dentler, W. (2013). Discovery and functional evaluation of ciliary proteins in Tetrahymena thermophila. Methods Enzymol 525: 265284.

5 Gorman, D. S. and Levine, R. P. (1965). Cytochrome f and plastocyanin: their sequence in the photosynthetic electron transport chain of Chlamydomonas reinhardi. Proc Natl Acad Sci U S A 54(6): 1665-1669.

6 Gorovsky, M. A., Yao, M. C., Keevert, J. B. and Pleger, G. L. (1975). Isolation of micro- and macronuclei of Tetrahymena pyriformis. Methods Cell Biol 9(0): 311-327.

7 Heuser, T., Raytchev, M., Krell, J., Porter, M. E. and Nicastro, D. (2009). The dynein regulatory complex is the nexin link and a major regulatory node in cilia and flagella. $J$ Cell Biol 187(6): 921-933.

8 Ichikawa, M., Khalifa, A. A. Z., Kubo, S., Dai, D., Basu, K., Maghrebi, M. A. F., Vargas, J. and 
Bui, K. H. (2019). Tubulin lattice in cilia is in a stressed form regulated by microtubule inner proteins. Proc Natl Acad Sci U S A 116(40):19930-19938.

9 Ichikawa, M., Liu, D., Kastritis, P. L., Basu, K., Hsu, T. C., Yang, S. and Bui, K. H. (2017). Subnanometre-resolution structure of the doublet microtubule reveals new classes of microtubule-associated proteins. Nat Commun 8: 15035.

10 Imhof, S., Zhang, J., Wang, H., Bui, K. H., Nguyen, H., Atanasov, I., Hui, W. H., Yang, S. K., Zhou, Z. H. and Hill, K. L. (2019). Cryo electron tomography with volta phase plate reveals novel structural foundations of the 96-nm axonemal repeat in the pathogen Trypanosoma brucei. Elife 8: e52058.

11 Khalifa, A. A. Z., Ichikawa, M., Dai, D., Kubo, S., Black, C. S., Peri, K., McAlear, T. S., Veyron, S., Yang, S. K., Vargas, J., Bechstedt, S., Trempe, J. F. and Bui, K. H. (2020). The inner junction complex of the cilia is an interaction hub that involves tubulin post-translational modifications. Elife 9: e52760.

12 Williams, N. E., Wolfe, J. and Bleyman, L. K. (1980). Long-term maintenance of Tetrahymena spp. J Protozool 27(3): 327. 